\title{
Profil Musiman Gelombang Laut di Laut Sulawesi
}

\author{
Achmad Fahruddin Rais \\ Stasiun Meteorologi Kotabaru \\ J1 Raya Stagen KM. I0 Kotabaru Kalimantan Selatan \\ Surat-e: achmad.rais@bmkg.go.id
}

\section{Rezky Yunita}

Stasiun Meteorologi Banjarmasin

Bandara Syamsudin Noor Banjarmasin

Surat-e: rezky.yunita@bmkg.go.id

Laut Sulawesi memiliki gelombang tinggi yang menyebabkan kecelakaan transportasi. Pemodelan global dan pengamatan satelit akan gelombang laut di Laut Sulawesi memiliki keterbatasan resolusi spasial dan temporal. Untuk mengevaluasi luaran gelombang signifikan model Wavewatch III (WW3), digunakan korelasi dan root mean square (RMSE) terhadap pengamatan satelit. Analisis temporal dan spasial menggunakan nilai rata-rata dan principal component analysis (PCA) ditujukan untuk mengetahui karakteristik musiman. Hasil evaluasi gelombang signifikan WW3 menunjukkan nilai yang baik secara umum (0.3-0.7) dengan RMSE bernilai 0.3-0.5 meter. Pola utama distribusi spasial gelombang signifikan memiliki pusat tertinggi di timur laut dan nilai temporal terbesar pada akhir dan awal tahun. Gelombang tinggi pada Laut Sulawesi disebabkan oleh intrusi gelombang monsun baratan yang berasal dari Samudera Pasifik bagian barat.

The Celebes Sea has high wave that may cause transportation accident. Global modeling and satellite observation of sea wave over the Celebes Sea have a limitation of spatial and temporal resolution. To evaluate significant wave of Wave watch III (WW3) model output, correlation and root mean square (RMSE) are used towards satellite observation. Spatial and temporal analysis based on mean values and principal component analysis are used to understand seasonal characteristic. Generally, WW3 significant wave evaluation result is good (0.3-0.7) with 0.3-0.5 meter of RMSE. Maximum area of significant wave spatial distribution main pattern is over northeastern Celebes Sea and maximum temporal pattern is in end and beginning of the year. High sea wave over the Celebes Sea is generated by westerly monsoon wave from western Pasific Ocean.

Kata kunci: Gelombang Laut, Laut Sulawesi, WW3

\section{Pendahuluan}

Kecelakaan transportasi laut dapat terjadi akibat beberapa faktor, antara lain cuaca buruk, kebakaran, stabilitas kapal, tidak ada daya apung cadangan akibat muatan yang berlebihan, kandas, terdampar, tubrukan, design dan struktur yang tidak sempurna, kelalaian manusia, dan tangki bahan bakar bocor [I]. Laut Sulawesi bukan hanya menawarkan keindahan terumbu karang Bunaken, tetapi juga memiliki gelombang laut tinggi yang merenggut nyawa melalui kecelakaan transportasi laut akibat cuaca [2].
Di Laut Sulawesi, pemodelan global gelombang laut tidak memperlihatkan variasi signifikan akibat resolusinya yang rendah [3]. Pengukuran gelombang signifikan menggunakan satelit gabungan telah mampu menggambarkan variasi gelombang laut di Laut Sulawesi, akan tetapi banyak variabilitas gelombang pada wilayah sempit yang belum tercakup akibat resolusinya yang rendah [4] dan deret waktu yang pendek karena pengumpulan data dimulai tahun 2009 [5]. Oleh karena itu, dibutuhkan model gelombang laut dengan resolusi dan akurasi tinggi yang dapat memberikan gambaran spesifik tentang Laut Sulawesi. 


\section{Kajian Pustaka}

Gelombang di laut dapat dibangkitkan oleh angin, sistem badai, gempa bumi dan gaya tarik bulan dan matahari. Gelombang yang dibangkitkan oleh angin adalah yang paling dominan dan sangat dipengaruhi oleh tiga faktor utama, yaitu durasi angin bertiup, kecepatan angin dan panjang jarak tempuh perjalanan gelombang dari awal pembangkitannya yang disebut fetch [6]. Semakin lama angin bertiup, semakin kuat kecepatan angin dan semakin besar jarak fetch maka semakin besar energi gelombang yang dibangkitkan. Peran angin dalam membangkitkan gelombang tidaklah linier [7][8]. Energi yang ditransformasikan dari angin menjadikan energi yang lebih tinggi pada gelombang dengan spektrum periode panjang. Akibat energi gelombang yang besar, gelombang merambat ke luar daerah pertumbuhannya dan berinteraksi dengan gelombang laut pada daerah lain. Tinggi gelombang signifikan hasil rekaman alat dengan tinggi rata-rata I/3 dari gelombang-gelombang tertinggi memiliki kesesuaian dengan observasi visual [9]

Model gelombang Wavewatch III (WW3) adalah model gelombang laut NOAA yang diperuntukkan untuk menggambarkan interaksi gelombang yang dibangkitkan oleh angin dan sangat baik untuk perairan yang bersifat terbuka (Sofian dan Wijanarto, 2012). WW3 melibatkan pendekatan fisis dan numerik interaksi atmosfer-laut. Kehandalan WW3 diuji terhadap satelit TOPEX/POSEIDON dengan nilai korelasi 0.9 dan root mean square (RMSE) 0.48 [I0], terhadap satelit altimeter gabungan AVISO dengan koefisien korelasi 0.8I dan RMSE 0.4I di perairan Bali [II] dan dengan koefisien korelasi 0.78 dan RMSE I.2 m di Selat Sunda [I2].

\section{Metode Penelitian/Eksperimen}

Untuk melakukan peneltian, penulis menggunakan data model gelombang WW3 dengan resolusi $0.125^{\circ} \times 0.125^{\circ}$ pada periode tahun I99I-2014 yang diperoleh dari Badan Informasi Geospasial (BIG). Data observasi yang digunakan adalah data satelit altimeter gabungan (JasonI, Envisat, Jason-2 dan Cryosat-2) dengan resolusi $\mathrm{I}^{0} \mathrm{xI}^{0}$ pada periode tahun 20I0-20I4. Wilayah kajian adalah I $18^{\circ}$ BT-I28 $8^{\circ}$ BT dan $0^{\circ}$ LU-6 $6^{\circ}$ LU (gambar I).

Metode yang digunakan dalam menilai kehandalan simulasi model dengan menghitung koefisien korelasi dan RMSE. Perata-rataan dan pencarian nilai maksimum absolut digunakan untuk menghasilkan klimatologi musiman gelombang laut. Penulis juga menggunakan metode principal component analysis (PCA). PCA adalah metode untuk menemukan kombinasi linear tunggal menjelaskan fraksi maksimal pada variansi keseluruhan data. Empirical orthogonal function (EOF) berkaitan dengan pola skala spasial dan principal component berkaitan deret waktu yang mempertimbangkan variabilitas data [I3].

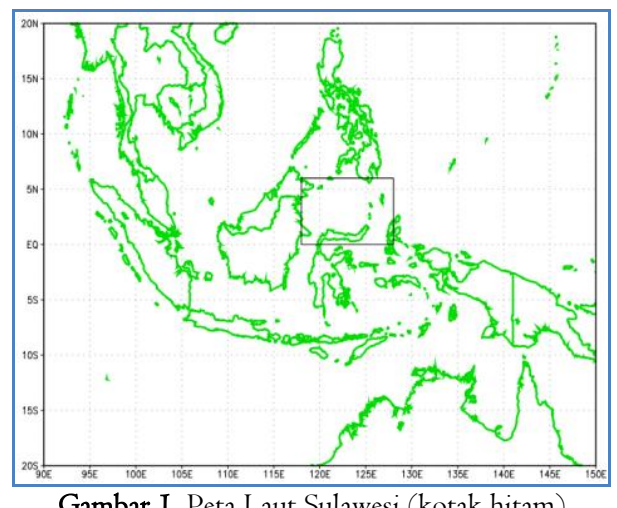

\section{Hasil Penelitian dan Pembahasan}

Umumnya, nilai korelasi bernilai positif berkisar antara 0.3 - 0.7 dimana menggambarkan hubungan yang selaras antara gelombang signifikan model WW3 dengan gelombang signifikan observasi satelit gabungan. Sebaran nilai korelasi tertinggi berada di bagian timur Laut Sulawesi yang berbatasan langsung dengan Samudera Pasifik bagian barat yang merupakan lautan terbuka dan nilai terendah berada di bagian utara dan barat Laut Sulawesi. Nilai RMSE berkisar antara 0.3 - 0.5 meter dengan distribusi nilai tertinggi di sebelah utara.

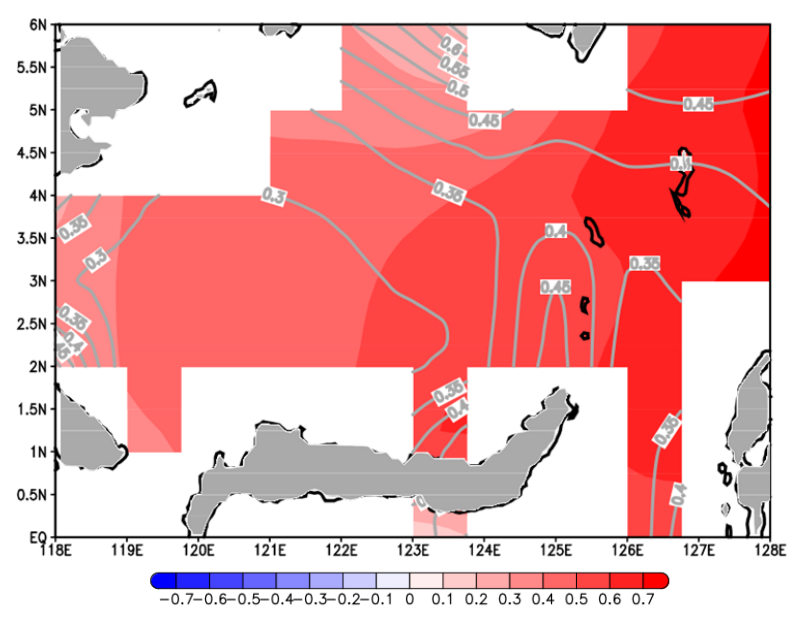

Gambar 2. Evaluasi gelombang signifikan model WW3 terhadap observasi satelit gabungan

Analisa EOF pada mode pertama (85.1\%) memperlihatkan pola spasial yang seragam (positif semua) dengan pusat nilai tertinggi berada pada Laut Sulawesi bagian timur laut. Mode pertama memiliki karakteristik menguat pada awal dan akhir tahun dan melemah pada pertengahan tahun, meskipun sedikit menguat pada bulan Juli dan Agustus. Lain halnya pada mode kedua (6.9 \%), sebaran spasial tidak seragam dengan perbedaan mencolok pada bagian timur laut dengan bagian utara sampai barat laut. Pada daerah dengan nilai spasial positif, mode kedua 
memiliki karakter menguat pada pertengahan tahun dan melemah pada awal dan akhir tahun, sedangkan berlaku pola sebaliknya pada daerah dengan nilai spasial negatif.
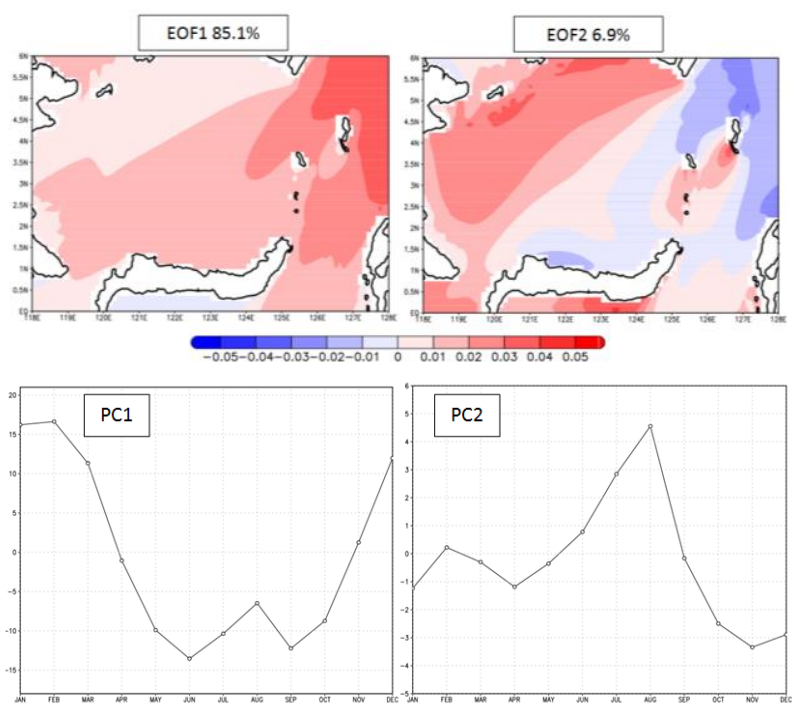

Gambar 3. Pola spasial EOFI dan EOF2 serta pola temporal PCI dan PC2

Pada periode Desember-Januari-Februari (DJF), sebaran gelombang signifikan rata -rata umumnya bervariasi antara lebih kecil dari $0.5 \mathrm{~m}$ sampai $2 \mathrm{~m}$ dengan sebaran nilai maksimum absolut terbesar mencapai 4.5 meter berada di bagian timur laut yang langsung berbatasan dengan Samudera Pasifik bagian barat. Di periode Maret-April-Mei (MAM), distribusi gelombang lebih rendah dibanding periode DJF yang berada pada kisaran lebih kecil dari 0.5 meter sampai I.5 meter dengan ketinggian maksimum 3.5 meter yang terletak pada wilayah yang sama dengan periode DJF. Ketinggian gelombang signifikan rata-rata pada periode Juni-JuliAgustus (JJA), masih memiliki kisaran yang sama dengan periode MAM, tetapi luasan sebaran gelombang signifikan rata-rata $>0.5$ meter lebih sempit dan nilai gelombang signifikan tertinggi pun lebih rendah dibandingkan periode sebelumnya. Sedangkan pada periode September-Oktober-November (SON), sebaran gelombang signifikan $>\mathrm{I}$ meter lebih luas dan nilai gelombang signifikan tertinggi lebih besar dibandingken periode JJA.

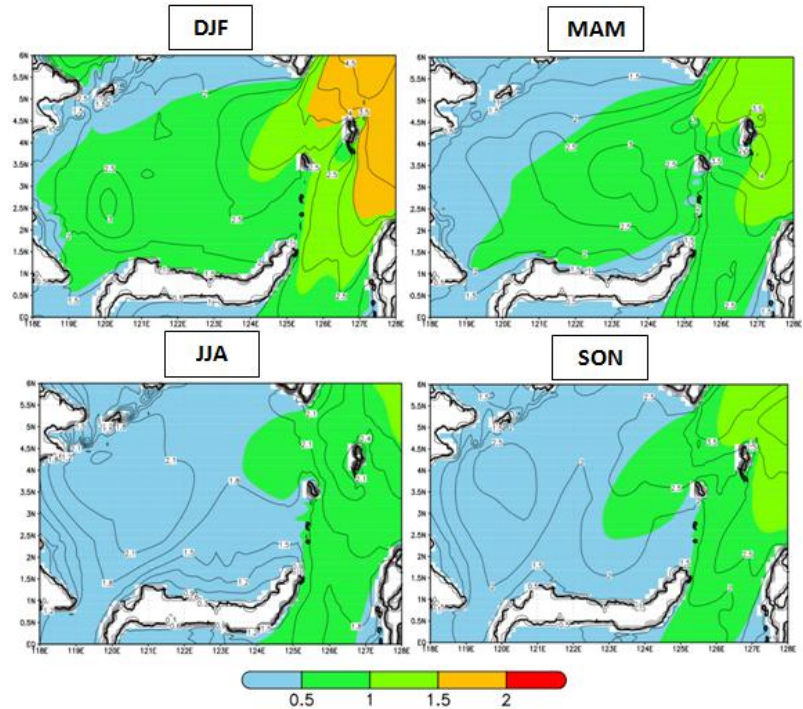

Gambar 4. Pola musiman gelombang signifikan dan maksimum absolut

Pola spasial tinggi gelombang signifikan rata-rata pada semua periode sama dengan pola spasial EOF mode pertama. Hal ini menunjukkan bahwa mode pertama bersifat nyata bukan hanya secara statistik dengan nilai prosentase variansi $85.1 \%$, melainkan juga secara fisik. Pola musiman gelombang signifikan menunjukkan adanya intrusi energi gelombang dari Samudera Pasifik bagian barat dan berinterferensi dengan gelombang yang dibangkitkan angin lokal di Laut Sulawesi. Intrusi energi gelombang diakibatkan oleh gelombang monsun baratan yang menguat pada awal dan akhir tahun (Hemer dkk., 20II).

\section{Kesimpulan}

Umumnya, evaluasi model gelombang signifikan WW3 menunjukkan hasil yang baik, meskipun memperlihatkan hasil yang kurang baik pada wilayah yang jauh dari lautan terbuka. Pola utama distribusi spasial gelombang signifikan adalah dengan pusat tertinggi di timur laut dan nilai temporal terbesar pada akhir dan awal tahun. Intrusi gelombang monsun baratan sangat mempengaruhi tinggi gelombang di Laut Sulawesi.

\section{Ucapan Terimakasih}

Ucapan terima kasih kami sampaikan kepada Dr. Ibnu Sofian dari Badan Informasi Geografis atas akses data gelombang signifikan model WW3. 


\section{Kepustakaan}

[I] Trans Asia Consultants. (2010). Kajian Analisis Trend Kecelakaan Transportasi Laut Tahun 2003 - 2008. Akses internet.

http://kemhubri.dephub.go.id/knkt/ntsc_maritime/Laut/Pub lications/Laporan\%

20Analisis\%20Trend\%20Kecelakaan\%20Laut\%2020032008.pdf

[2] Jasa Raharja. (6 Februari 2016). Akses internet. http://www.bumn.go.id/jasaraharja/berita/2365/ Kecelakaan.Kapal.Laut.Bunaken-Manado,.Sulawesi.Utara

[3] Hemer, M., Jack Katzfey and Claire Hotan. (20II). The windwave climate of the Pacific Ocean. Akses internet https://www.environment.gov.au/system/files/pages/275228 c5-24db-47f2-bf4I-82ef42cda73d/files/wind-wave-report.pdf

[4] Aziz, W. A. Wan Abdul, Omar Yakoob, Kamaludin Mohd Omar, dan Ami Hassan Md Din. (2012). Satellite Altimeter Ocean Wave Height Data In South China Sea. International Conference on Marine Technology Malaysia.

[5] Khotimah, Mia Khusnul. (2012). Validasi Tinggi Gelombang Signifikan Model Gelombang Windwave-5 dengan Menggunakan Hasil Pengamatan Satelit Altimetri Multimisi. Tesis. Fakultas Matematika dan Ilmu Pengetahuan Alam. Universitas Indonesia.

[6] Davis, R.A. Jr. (I99I). Oceanography: An Introduction to the Marine Envitonmen. New Jersey. WCB Publisher International Published.
[7] Hasselmann, K. (I963). On the Non-linear Energy Transfer in a Gravity Wave Spectrum, Part 2. Conservation Theorems, Wave-particle Analogy and Irreversibility. Journal of Fluid Mechanic, I5 (3) : 385-398.

[8] Hasselmann, K. (1966). Feynman Diagram and Interaction Rules of Wave - Wave Scattering Processes. Rev. Geophysical. $4(\mathrm{I}): \mathrm{I}-32$

[9] WMO. (1998). Guide to Wave Analysis and Forecasting, Second Edition. Geneva. Switszerland.

[I0] Chu, P. C., Qi, Y., Chen, Y., Shi., P., dan Mao, Q. (2004). South China Sea Wind-Wave Characteristic, Part I : Validation of Wavewatch-III Using TOPEX/POSSEIDON data. Journal of Atmospheric and Oceanic Technology, I718-1733.

[II] Mujiasih, Subekti dan Andri Ramdhani (20I4). Verifikasi Angin dan Gelombang Luaran Model Wavewatch III (WWIII) Terhadap Data Satelit di Wilayah Perairan Bali. Seminar Nasional Kelautan 2014

[I2] Isniarny, Nadya. (2012). Pemanfaatan data Angin Model GFS untuk Prediksi Tinggi Gelombang (Windwaves) menggunakan Model Wavewatch III (Studi Kasus di selat Sunda). Penerbitan Online Awal. Program Studi Meteorologi Institut Teknologi Bandung.

[13] Preisendofer, R. W. (1988). Principal Component Analysis in Meteorology and Oceanography. Elsevier. ISBN 9780444417107 